\title{
Comparative efficacy of a multi-epitope DNA vaccine via intranasal, peroral, and intramuscular delivery against lethal Toxoplasma gondii infection in mice
}

Hua Cong ${ }^{1 *}$, Quan Yuan ${ }^{2}$, Qunli Zhao ${ }^{1}$, Lingxiao Zhao ${ }^{1}$, Huiquan Yin ${ }^{1}$, Huaiyu Zhou ${ }^{1}$, Shenyi He ${ }^{1}$ and Zhiyu Wang ${ }^{3^{*}}$

\begin{abstract}
Background: Toxoplasmosis is an important zoonosis, being a cause of congenital disease and abortion in animals and humans. DNA vaccination as a promising vaccine remains a challenge for an improved delivery system.

Methods: In this study, attenuated Salmonella typhimurium BRD509 was used to deliver a DNA vaccine encoding several epitopes, derived from the tachyzoite proteins SAG1, GRA1, ROP2, GRA4 and bradyzoite proteins SAG2C, SAG2X of Toxoplasma gondii and $\mathrm{A}_{2} / \mathrm{B}$ subunit of cholera toxin. The recombinant plasmids were electroporated into attenuated Salmonella typhimurium. Humoral and cellular immune responses were evaluated for BALB/C mice administered with this attenuated recombinant Salmonella vaccine via the oral and nasal route or by intramuscular injection with DNA plasmid directly.
\end{abstract}

Results: High IgG levels were present in the mice immunized intramuscularly, while IgA levels were higher in the oral and nasal immunization groups. Furthermore, cellular immunity was activated in oral immunization groups with $60 \%$ survival rate following challenge with high virulent $\mathrm{RH}$ strain.

Conclusions: The results from this study indicate that a DNA vaccine encoding multi-epitopes of T. gondii delivered by attenuated Salmonella is promising.

Keywords: Toxoplasma gondii, Multi-epitopes, Salmonella typhimurium, Vaccine

\section{Background}

Toxoplasma gondii is a single-cell obligate intracellular protozoan, which is widely prevalent in humans and animals $[1,2]$. This parasite is of major medical and veterinary importance, being a cause of congenital disease and abortion $[3,4]$. Despite many efforts and significant advances in the understanding of the immune responses that occur after infection by $T$. gondii, animal experiments have shown that the effect of monovalent antigen vaccine is not ideal [5-7]. Therefore, the development of a variety of antigen combinations for different stages of life cycle, especially epitopes from tachyzoites and

\footnotetext{
* Correspondence: conghua@sdu.edu.cn; zhiyu.wang@sdu.edu.cn 'Department of human parasitology, Medical school, Shandong University, No.44 Wenhuaxi Road, Jinan, Shandong 250012, P. R. China

${ }^{3}$ School of Public Health, Shandong University, No.44 Wenhuaxi Road, Jinan, Shandong 250012, P. R. China

Full list of author information is available at the end of the article
}

bradyzoites are likely to be needed for full protection [8-11]. We constructed a DNA vaccine encoding five epitopes of $T$. gondii previously. The vaccination injected intramuscularly into BALB/c resulted in an improvement of the humoral and cellular immune response in immunized mice, but there was only $20 \%$ survival rate achieved in vaccinated mice [12]. In order to broaden the immunogenicity, we intend to include more epitopes from various proteins of tachyzoites and bradyzoites in the vaccine construction. Other than epitopes from tachyzoite proteins SAG1, GRA1, ROP2, GRA4, epitopes from bradyzoite proteins SAG2C, SAG2X were also included [13,14].

However, DNA vaccines have been used to inject intramuscularly as naked DNA using a gene gun and by subcutaneous inoculation. After vaccination, only a limited amount of DNA reaches professional APCs 
cells [15]. Mechanisms to induce a more effective immune response and to improve protection from immunized mice remains to be determined. Recombinant Salmonella have been used as vaccine vectors to deliver both DNA and protein vaccines from a wide variety of bacterial, viral and parasitic sources $[16,17]$. Attenuation virulence bacteria, which can penetrate host cells delivering vaccine antigen to APCs, can be used effectively to transport immunogens $[18,19]$.

In this study, a recombinant attenuated Salmonella DNA vaccine encoding multi-epitopes of $T$. gondii and $\mathrm{A}_{2} / \mathrm{B}$ subunits of cholera toxin was constructed. The immunity induced by this attenuated recombinant Salmonella vaccine administered orally and nasally in BALB/c mice was compared to immunity induced by a plasmid DNA vaccine injected into mice intramuscularly. Protection against challenge with high virulent $\mathrm{RH}$ strain of $T$. gondii was evaluated.

\section{Methods}

\section{Parasites and bacterial strain}

Tachyzoites of the high virulent $\mathrm{RH}$ strain of $T$. gondii were cryopreserved in our laboratory. Parasites were maintained by serial intraperitoneal passage in BALB/C mice. Tachyzoites were harvested from the peritoneal fluid of mice after $72 \mathrm{~h}$, and used to challenge immunized mice.

Salmonella typhimurium strain BRD509 is an aroA and $\operatorname{aroD}^{-}$mutant of SL 1344 [20]. This was kindly provided by Dr. Jifeng Bian, the Department of Molecular Biology, Shandong University.

\section{Construction of recombinant Salmonella}

The oligonucleotides of multi-epitope genes (MEG) were designed based on the $T$. gondii peptide sequences: SAG1-I 59-67 (TCPDKKSTA), SAG1-II 246-255 (ILPKLTENPW), GRA1 176-186(DTMKSMQRDED), ROP2 200-215 (GDV VIEELFNRIPETS), GRA4 235-243 (SGLTGVKDS), SAG 2C 36-44 (SQFLSLSLL), SAG2X 215-223 (AAGTTAT $\mathrm{AV})$. The construction of pVAX1-MEG-CTXA 2 /B was shown in Figure 1.

Attenuated recombinant Salmonella carrying pVAX1MEG-CTXA 2 /B was generated by electroporation. pVAX1MEG-CTXA 2 /B plasmid was transferred into $100 \mu \mathrm{l}$ competent S. typhimurium BRD509 in the condition of $2.5 \mathrm{kV}, 25 \mathrm{uF}, 5 \mathrm{~ms}$. To produce inocula, recombinant Salmonella were incubated overnight at $37^{\circ} \mathrm{C}$ until an $\mathrm{OD}_{600}$ of 0.8 was reached, then washed and resuspended in PBS to a final density of approximately $1-5 \times 10^{9} \mathrm{cfu}$.

\section{Vaccinations and challenges}

SPF BALB/c female mice (6-8 weeks old) were used in the immunization and parasite challenge. They were purchased from The Laboratory Animal Center of Shandong University. All studies were conducted with Animal Care and Use Committee of Shandong University approval.

The mice were randomly divided into intraoral, intranasal and intramuscular immunization groups (30 mice per group). Table 1 summarizes the treatments performed in
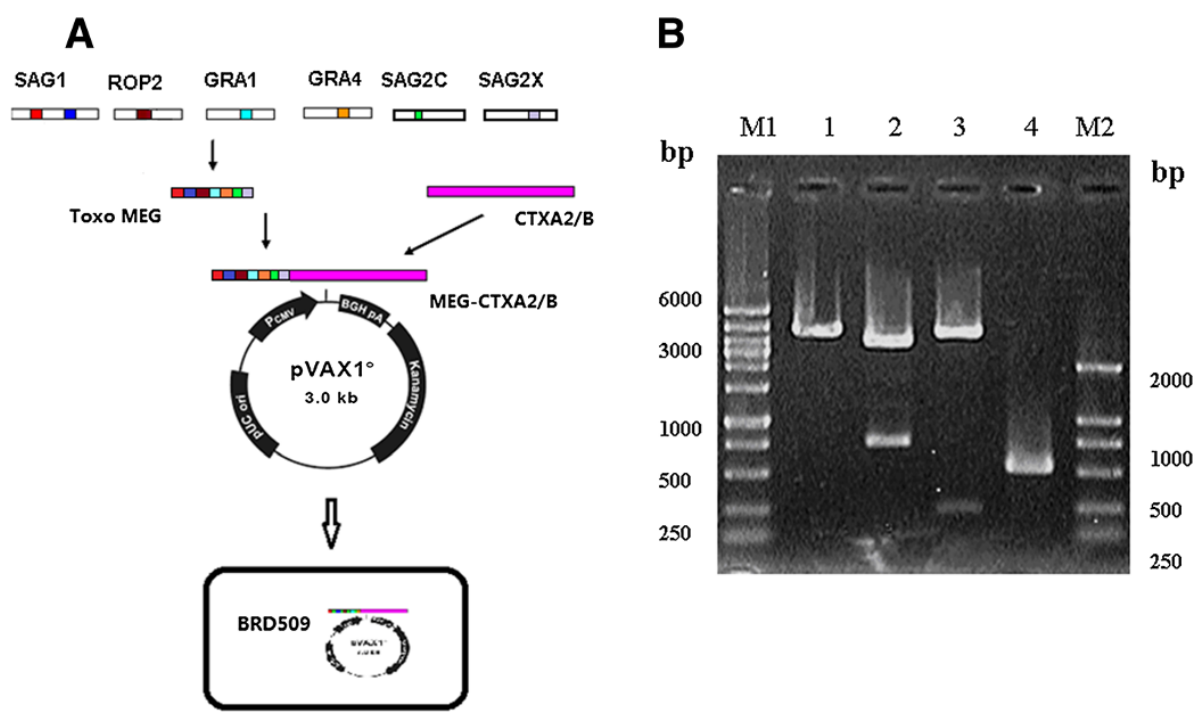

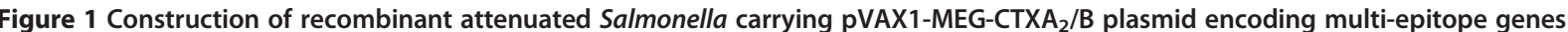
derived from $T$. gondii and $\mathrm{A}_{2} / \mathrm{B}$ subunits of cholera toxin. (A) The diagram of the construction of recombinant attenuated Salmonella. (B) Gel electrophoresis analysis of pVAX1-MEG-CTXA $/$ B plasmid encoding multi-epitope genes of Toxoplasma gondii. Lane M1: DNA Marker D, L 100 + 6000, Lane M2: DNA Marker DL2000, Lane1: pVAX1-MEG-CTXA /B plasmid digested by EcoR I, Lane 2: pVAX1-MEG-CTXA2/B plasmid digested by Hind III and EcoR I, Lane 3: pVAX1-MEG-CTXA 2 /B digested by Hind III and Kpn I, Lane4: PCR product of CTXA $/$ B. 
Table 1 Summary of treatments performed in the BALB/c mice

\begin{tabular}{|c|c|c|c|c|c|}
\hline \multirow[t]{2}{*}{ Groups } & \multirow[t]{2}{*}{ Route of administration } & \multirow[t]{2}{*}{ Treatments $^{\mathrm{a}}$} & \multicolumn{3}{|c|}{ Mice number } \\
\hline & & & Total mice & In $\mathrm{HI}^{\mathrm{b}}$ and $\mathrm{CMI}^{\mathrm{c}}$ & In challenge ${ }^{d}$ \\
\hline \multirow[t]{3}{*}{ । } & Intramuscular vaccination & $100 \mu \mathrm{l}$ PBS & 10 & 3 & 7 \\
\hline & & $100 \mu \mathrm{g}$ pVAX1 & 10 & 3 & 7 \\
\hline & & $100 \mu \mathrm{g}$ pVAX1-MEG-CTXA $2 / B$ & 10 & 3 & 7 \\
\hline \multirow[t]{3}{*}{$\|$} & Intranasal vaccination & $200 \mu \mathrm{l} \mathrm{BRD509}$ & 10 & 3 & 7 \\
\hline & & $200 \mu \mathrm{l}$ BRD509/pVAX1 & 10 & 3 & 7 \\
\hline & & $200 \mu \mathrm{l}$ BRD509/pVAX1-MEG-CTXA $2 / B$ & 10 & 3 & 7 \\
\hline \multirow[t]{3}{*}{ III } & Intraoral vaccination & $50 \mu \mathrm{l} \mathrm{BRD509}$ & 10 & 3 & 7 \\
\hline & & $50 \mu \mathrm{l} \mathrm{BRD509/pVAX1}$ & 10 & 3 & 7 \\
\hline & & $50 \mu \mathrm{l}$ BRD509/pVAX1-MEG-CTXA $/$ B & 10 & 3 & 7 \\
\hline
\end{tabular}

${ }^{a}$ The mice were randomly divided into intramuscular, intranasal and intraoral immunization groups (30 mice per group). For the intramuscular group, the mice were injected $100 \mu \mathrm{l} 1 \mu \mathrm{g} / \mu \mathrm{l}$ recombinant plasmid or empty plasmid in the quadriceps muscle; For the nasal group, each mouse was given a nasal drip of $50 \mu \mathrm{l}$ $10^{9} \mathrm{cfu} / \mathrm{ml}$ Salmonella bacteria with recombinant plasmid or empty plasmid; The oral group was administrated $200 \mu \mathrm{l} 10^{9} \mathrm{cfu} / \mathrm{ml} \mathrm{Salmonella}$ bacteria with recombinant plasmid or empty plasmid orally; Each group also had 10 mice which were treated with Salmonella without plasmid or saline as negative control. Mice were vaccinated three times at 2 week intervals.

${ }^{\mathrm{b}}$ Humoral immunity $(\mathrm{HI})$ was tested by collecting sera from three immunized mice in each group.

${ }^{c}$ Cellular immunity (CMI) was evaluated by splenocytes from three immunized mice per group 2 weeks after the last immunization.

${ }^{\mathrm{d}}$ Four weeks after the last immunization, immunized mice were challenged intraperitoneally with $1 \times 10^{3}$ tachyzoites of $T$. gondii RH strain.

the mice. Mice were vaccinated three times at 2 weeks intervals. Blood was collected by orbital plexus puncture and sera were stored at $-70{ }^{\circ} \mathrm{C}$ for further analysis.

For challenge study, immunized mice were challenged intraperitoneally with $1 \times 10^{3}$ tachyzoites of RH strain $T$. gondii 4 weeks after the last immunization. The survival time and the survival rate was measured.

\section{Measurement of humoral antibodies response}

To measure $T$. gondii-specific total IgG and IgA, plates (Dursley, UK) were coated with $10 \mathrm{ug} / \mathrm{ml}$ solution of STAg at $4^{\circ} \mathrm{C}$ overnight. Sera were diluted in 1\% PBST-20 (1:100) and incubated in the plates for $1 \mathrm{~h}$ at room temperature (RT). After washing the plates, Horseradish peroxidase (HRP)-conjugated goat anti-mouse IgG, IgA (SouthernBiotech, USA) were further incubated for $1 \mathrm{~h}$ at RT. Peroxidase activity was revealed by $3,3^{\prime}, 5,5^{\prime}$ tetramethylbenzidine $(\mathrm{TMB}, 10 \mathrm{mg} / \mathrm{ml}$ ) and stopped by adding $50 \mu \mathrm{l}$ of $2 \mathrm{M} \mathrm{H}_{2} \mathrm{SO}_{4}$. The optical density (OD) was read out at $450 \mathrm{~nm}$ in a microplate reader (Bio-TEK, USA).

\section{Proliferation assays}

Spleens from three immunized mice per group were removed 2 weeks after the last immunization. The splenocytes were adjusted to a concentration of $5 \times 10^{6}$ cells/ $\mathrm{ml}$ in DMEM with 10\% FCS. The suspension of $100 \mu \mathrm{l}$ in each well was cultured with STAg $(10 \mu \mathrm{g} / \mathrm{ml})$, purified rMEG protein $(50 \mu \mathrm{g} / \mathrm{ml})$ or concanavalin A (Con A, $5 \mu \mathrm{g} / \mathrm{ml}$; Sigma). Cell proliferative activity was measured according to instructions described in a previous study [21].

\section{T lymphocyte subsets analysis}

Cells were stained with FITC-labeled anti-mouse $\mathrm{CD}^{+}$ monoclonal antibody and PE-labeled anti-mouse $\mathrm{CD} 4^{+}$ monoclonal antibody, $\mathrm{T}$ lymphocyte subsets were measured using flow cytometry (Beckman Coulter, USA).

\section{Cytokine assays}

Splenocytes from immunized mice were cultured with rMEG protein as described for lymphocyte proliferation assays. Commercial ELISA kits (mouse IL-4 OptEIA, IL5 OptEIA, IFN- $\gamma$ OptEIA, IL-2 OptEIA, Endogen, USA) were used according to the manufacturer's instructions to assay cytokine levels in culture supernatants obtained at $24 \mathrm{~h}$ for IL-4, at $36 \mathrm{~h}$ for IL-5, at $72 \mathrm{~h}$ for IL-2 and at $96 \mathrm{~h}$ for IFN- $\gamma$.

\section{Statistical analysis}

The statistically significant differences between groups were calculated with one-factor analysis of variance (ANOVA). Differences were considered to be significant with $\mathrm{p}<0.05$.

\section{Results}

\section{Construction of recombinant Salmonella}

The diagram for multi-epitope DNA vaccine of T. gondii is shown on Figure 1A. Recombinant Salmonella carrying pVAX1-MEG-CTXA $\mathrm{A}_{2} / \mathrm{B}$ plasmid were identified by enzyme digestion, by PCR (Figure $1 \mathrm{~B}$ ) and further confirmed by sequencing.

\section{Humoral immune response}

IgG antibody levels in mouse serum indicates that pVAX1MEG-CTXA 2 /B DNA plasmid inoculated intramuscularly 
induced higher levels of IgG than mice immunized with BRD509/pVAX1-MEG-CTXA 2 /B orally and intranasally, $\mathrm{p}<0.05$ (Figure 2A). On the other hand, higher levels of anti- $T$. gondii IgA were detected in the serum of mice immunized with BRD509/pVAX1-MEG-CTXA $2 / B$ via the oral and nasal route than in the serum of mice injected intramuscularly with pVAX1-MEG-CTXA $2 / B$ plasmid $(\mathrm{p}<0.05)$ (Figure 2B).

\section{Cellular immune response analysis}

$\mathrm{CD}^{+}$and $\mathrm{CD}^{+} \mathrm{T}$ lymphocyte subsets in immunized mice were assayed by flow cytometry. Table 2 shows the percentage of $\mathrm{CD}^{+}$and $\mathrm{CD}^{+}$T-cell. The percentage of $\mathrm{CD} 8^{+}$ $\mathrm{T}$ cells in mice immunized intramuscularly with pVAX1MEG-CTXA 2 /B plasmid was $28.54 \pm 0.92 \%$. A even higher percentage of $\mathrm{CD}^{+} \mathrm{T}$ cells, $30.01 \pm 1.78 \%$, was achieved in mice immunized intranasally with BRD509/ pVAX1-MEG$\mathrm{CTXA}_{2} / \mathrm{B}$. The highest percentage of $\mathrm{CD}^{+} \mathrm{T}$-cell, $35.55 \pm$ $0.70 \%$, was achieved in mice immunized orally with BRD509/pVAX1-MEG-CTXA 2 /B (Table 2). Culture supernatants from antigen-stimulated splenocytes from mice in these groups were quantified with sandwich ELISA for
Th1 and Th2 cytokines. As shown in Table 3, culture supernatant cytokines from the mice vaccinated intramuscularly with pVAX1-MEG- CTXA ${ }_{2} / \mathrm{B}$ demonstrated preferential production of IFN- $\gamma$ and IL-2, which were significantly higher than that of control groups $(\mathrm{p}<0.05)$. The amounts of IFN- $\gamma$ and IL- 2 were significantly higher in the mice via oral and intranasal immunization with recombinant Salmonella BRD509 than the mice immunized intramuscularly $(p=0.02)$. However, the levels of IL-4 and IL-5 produced by immunized mice were low, and no statistically significant differences were present between vaccinated groups and control groups $(\mathrm{p}>0.05)$. Furthermore, antigen specific lymphocyte proliferation activity was highly enhanced for BRD509/pVAX1-MEG-CTXA $2 / B$ oral and intranasal immunization groups than for the pVAX1-MEG$\mathrm{CTXA}_{2} / \mathrm{B}$ intramuscular immunization group $(\mathrm{p}<0.05)$.

\section{Challenge study}

Four weeks after the last immunization, mice were challenged with 100 ul $1 \times 10^{3}$ tachyzoites of $T$. gondii RH strain intraperitoneally. All the control mice died. Mice treated with saline died within 4 days. Mice immunized
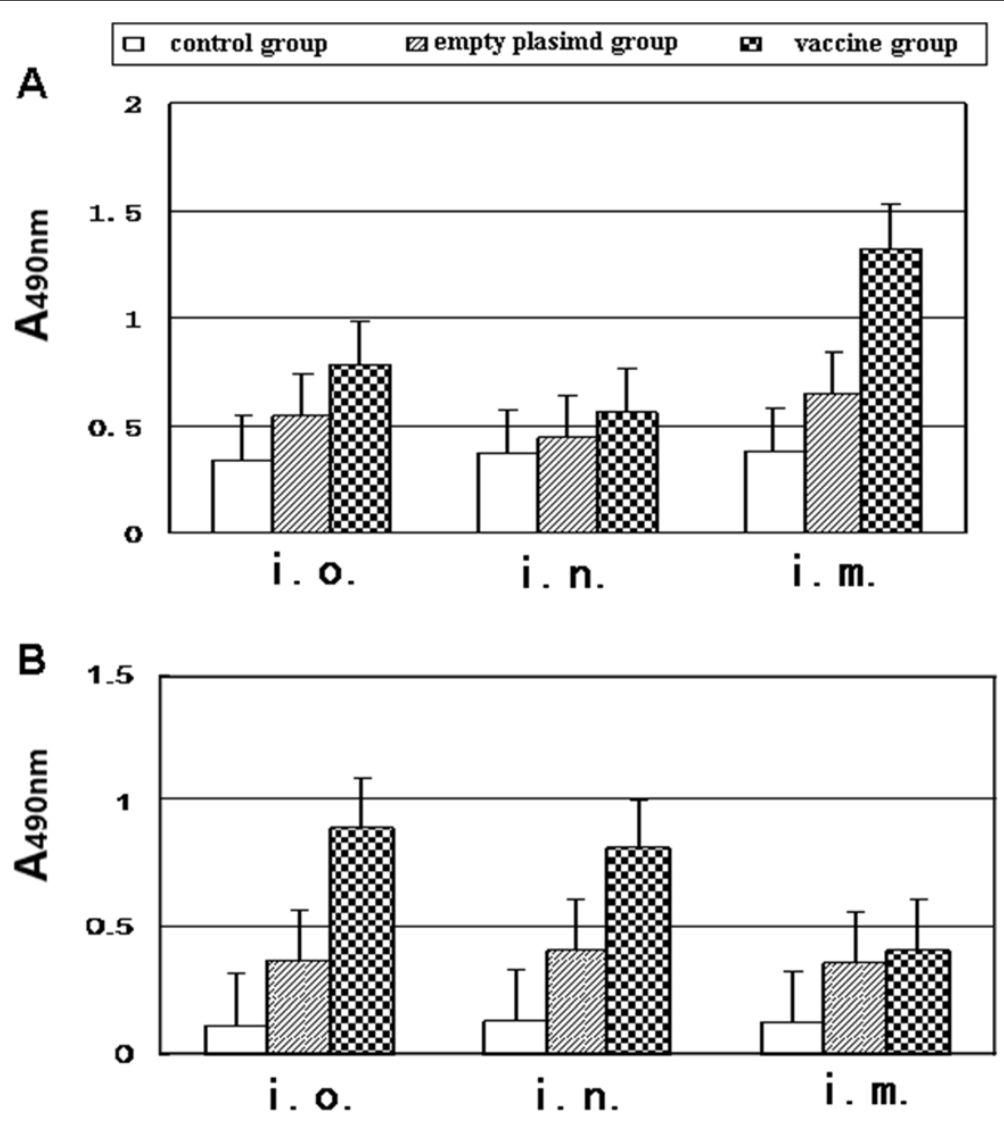

Figure 2 Specific humoral response to native $T$. gondii antigens in mice immunized with multi-epitope DNA vaccine was measured using ELISA 2 weeks after the last immunization. (A) Total Anti-T. gondii lgG; (B) Anti-T. gondii lgA were tested by sera diluted 1:200 from BALB/C mice via three different immunized routes: i.o.( intraoral); i.n. (intranasal); i.m. (intramuscular). 
Table 2 CD4, CD8 $^{+}$subtypes of T cells from immunized mice were measured using flow cytometry

\begin{tabular}{llll}
\hline $\begin{array}{l}\text { Immunization } \\
\text { route }^{\mathbf{a}}\end{array}$ & $\begin{array}{l}\text { Immunization } \\
\text { regimen }\end{array}$ & CD4 $^{+}(\%)^{\mathbf{b}}$ & $\mathbf{C D 8}^{+}(\%)^{\mathbf{b}}$ \\
\hline Intramuscular & PBS & $26.71 \pm$ & $21.67 \pm$ \\
vaccination & & 1.32 & 0.82 \\
& pVAX1 & $25.45 \pm$ & $22.37 \pm$ \\
& pVAX1-MEG-CTXA $/$ B & $24.56 \pm$ & $28.54 \pm$ \\
& & 1.25 & 0.92 \\
Intranasal vaccination & BRD509 & $25.71 \pm$ & $22.37 \pm$ \\
& & 0.64 & 0.83 \\
& BRD509/pVAX1 & $24.32 \pm$ & $26.34 \pm$ \\
& & 1.75 & 0.93 \\
& BRD509/pVAX1-MEG- & $24.68 \pm$ & $30.01 \pm$ \\
& CTXA $/$ B & 1.43 & 1.78 \\
Intraoral vaccination & BRD509 & $27.45 \pm$ & $24.38 \pm$ \\
& & 1.91 & 0.98 \\
& BRD509/pVAX1 & $24.32 \pm$ & $30.28 \pm$ \\
& & 1.21 & 0.53 \\
& BRD509/pVAX1-MEG- & $25.15 \pm$ & $35.55 \pm$ \\
& CTXA $/$ B & 1.55 & 0.70 \\
\hline
\end{tabular}

${ }^{\mathrm{a}}$ Mice were immunized by three immunization routes, intramuscular, intraoral, intranasal, on day 0 and day 14 and day 28 with different immunization regimens.

${ }^{\mathrm{b}}$ The splenocyte culture supernatants taken from mice $(\mathrm{n}=3$, each group) 2 weeks after the last immunization were stained with FITC-labeled anti-mouse $\mathrm{CD}^{+}$monoclonal antibody and PE-labeled anti-mouse $\mathrm{CD}^{+}$monoclonal antibody, $T$ lymphocyte subsets were measured using flow cytometry.

with empty plasmid intramuscularly died within 5 days. Mice treated orally with empty Salmonella died within 8 days. While there was a $20 \%$ survival rate $(2 / 10)$ for the mice immunized with pVAX1-MEG-CTXA $2 / B$ plasmid intramuscularly. The recombinant Salmonella BRD509/ pVAX1-MEG-CTXA $A_{2} / \mathrm{B}$ intranasal immunization group had $40 \%$ survival rate $(4 / 10)$ after 10 days. The highest survival rate of $60 \%(6 / 10)$ was achieved in the mice orally immunized with recombinant Salmonella BRD509/ pVAX1-MEG-CTXA ${ }_{2} /$ B (Figure 3).

\section{Discussion}

Recently, considerable efforts have been devoted to the development of nucleic acid vaccine to protect against T. gondii [22-25]. However, because of the complexity of the parasite life cycle and the variability of the parasite antigens, multi-epitope vaccines have become an attractive strategy for development of vaccines against this parasite [26-28]. In this study, a DNA vaccine encoding seven epitopes of $T$. gondii, derived from the tachyzoite proteins SAG1, GRA1, ROP2, GRA4 and bradyzoite proteins SAG2C, SAG2X of T. gondii, were constructed and linked to $\mathrm{A}_{2} / \mathrm{B}$ subunit of cholera toxin.

However, DNA vaccine as a promising vaccine remains a challenge for an improved delivery system. Mucosal vaccines can enhance mucosal and systemic humoral immunity especially for intracellular parasites such as $T$. gondii $[29,30]$. Thus, the best way for a vaccine to induce mucosal immunity is directly by inoculation of the mucosal surface. In this study, attenuated strains of S. typhimurium BRD509 were used as vaccine vectors to deliver heterologous antigens to the mucosal surface of the vaccine recipients [31,32]. A recombinant attenuated $S$. typhimurium vaccine encoding a multi-epitope gene of $T$. gondii was constructed. The mice were given inoculations via oral, nasal, or muscular routes. Immune responses induced by oral or nasal immunization with attenuated recombinant Salmonella BRD509 vaccines were compared to immune response induced by immunization with the plasmid pVAX1-MEG-CTXA 2 /B DNA vaccine intramuscularly.

The results showed intramuscular immunization of mice induced higher levels of IgG antibodies than attenuated

Table 3 Cell proliferative assay and cytokine production in the splenocyte cultures obtained from immunized mice

\begin{tabular}{|c|c|c|c|c|c|c|}
\hline \multirow[t]{2}{*}{ Immunization route ${ }^{a}$} & \multirow[t]{2}{*}{ Immunization regimen } & \multicolumn{5}{|c|}{ Cytokine production $(\mathrm{pg} / \mathrm{ml})^{\mathrm{b}}$} \\
\hline & & IL-2 & IFN-Y & IL-4 & IL-5 & $S I^{c}$ \\
\hline \multirow[t]{3}{*}{ Intramuscular vaccination } & Saline & $12 \pm 3$ & $13 \pm 8$ & $<10$ & $<10$ & 0.23 \\
\hline & pVAX1 & $16 \pm 4$ & $15 \pm 5$ & $11 \pm 8$ & $<10$ & 0.51 \\
\hline & pVAX1-MEG-CTXA $/$ /B & $93 \pm 21$ & $385 \pm 64$ & $15 \pm 7$ & $13 \pm 6$ & 1.61 \\
\hline \multirow[t]{3}{*}{ Intranasal vaccination } & BRD509 & $13 \pm 4$ & $14 \pm 5$ & $<10$ & $17 \pm 5$ & 0.75 \\
\hline & BRD509/pVAX1 & $14 \pm 7$ & $15 \pm 6$ & $<10$ & $19 \pm 5$ & 1.07 \\
\hline & BRD509/pVAX1-MEG-CTXA $/$ /B & $105 \pm 30$ & $412 \pm 24$ & $23 \pm 6$ & $<10$ & 2.12 \\
\hline \multirow[t]{3}{*}{ Intraoral vaccination } & BRD509 & $12 \pm 5$ & $15 \pm 4$ & $<10$ & $16 \pm 8$ & 0.75 \\
\hline & BRD509/pVAX1 & $15 \pm 7$ & $18 \pm 4$ & $<10$ & $16 \pm 7$ & 1.45 \\
\hline & BRD509/pVAX1-MEG-CTXA $2 / B$ & $121 \pm 36$ & $507 \pm 16$ & $<10$ & $12 \pm 4$ & 2.85 \\
\hline
\end{tabular}

${ }^{a}$ Mice were immunized by three immunization routes, intramuscular, intraoral, intranasal on day 0 and day 14 and day 28 with different immunization regimens. ${ }^{\mathrm{b}}$ The splenocyte culture supernatants taken from mice $(n=3$, each group) 2 weeks after the last immunization were examined for cytokine production by sandwich ELISA obtained at $24 \mathrm{~h}$ for IL-4, at $36 \mathrm{~h}$ for IL-5, at $72 \mathrm{~h}$ for IL-2 and $96 \mathrm{~h}$ for IFN- .

'The results of proliferation assays are expressed as the stimulation index (SI), calculated as the ratio between the mean counts per minute (cpm) for triplicate stimulated cultures and the mean counts per min for triplicate unstimulated cultures. SI values 2.5 -fold greater than the SI of the control groups were considered as significant. 

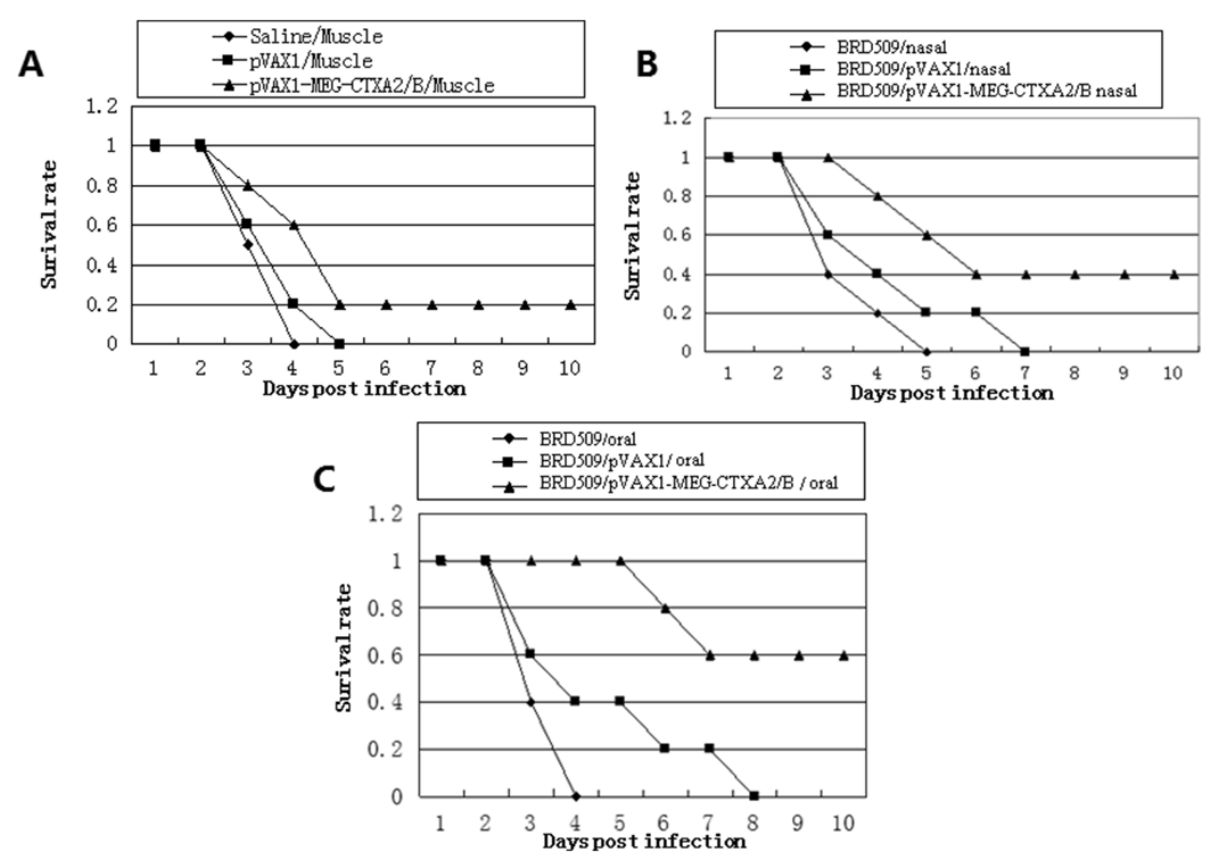

Figure 3 Survival curves of immunized mice after challenge with $10^{3}$ tachyzoite forms of RH $T$. gondii strain 4 weeks after the last immunization. (A) Intramuscular immunization group, the mice were injected with $100 \mu \mathrm{l} 1 \mu \mathrm{g} / \mu \mathrm{l}$ recombinant plasmid, empty plasmid or PBS in the quadriceps muscle; (B) Nasal immunization group, each mouse was given a nasal drip of $50 \mu \mathrm{l} 10^{9} \mathrm{cfu} / \mathrm{ml}$ Salmonella bacteria with recombinant plasmid, empty plasmid or empty bacteria; (C) Oral immunization group, the mice were administrated orally with $200 \mu \mathrm{l} 10^{9} \mathrm{cfu} / \mathrm{ml}$ Salmonella bacteria with recombinant plasmid, empty plasmid, or empty bacteria.

recombinant Salmonella vaccine immunization via oral and nasal routes. However, the attenuated recombinant Salmonella oral and intranasal immunization induced higher levels of IgA antibodies than intramuscular immunization. IgA is important in mucosal immunity to oral infection with toxoplasma cysts. Since antibodies of this isotype are important in preventing re-infection with $T$. gondii, inducing IgA may be a major strategic aspect of vaccine development [33,34].

Major mechanisms by which immunocompetent hosts control $T$. gondii infections is thought to be the strong and persistent cell-mediated immunity elicited by parasites $[35,36]$. In this study, splenocyte proliferation was enhanced in mice immunized by all three routes. Proliferation activity was significantly enhanced in mice immunized with recombinant attenuated Salmonella BRD509 via oral and nasal routes.

Both $\mathrm{CD}^{+}$and $\mathrm{CD}^{+} \mathrm{T}$ cell subsets play a central role in the establishment of protective immunity in hosts. In this study, CD4 ${ }^{+}$and $\mathrm{CD} 8^{+} \mathrm{T}$ lymphocytes subsets from immunized mice were assayed by flow cytometry. There was a marked increase in the percentage of $\mathrm{CD}^{+} \mathrm{T}$-cells in mice immunized with the recombinant attenuated Salmonella BRD509 vaccine perorally. As we know, the memory T-cell consists of $\mathrm{CD}^{+}{ }^{+}$and $\mathrm{CD}^{+} \mathrm{T}$-cells, which can rapidly acquire effector functions to kill infected cells and secrete inflammatory cytokines that inhibit replication of the pathogen. Effector $\mathrm{CD}^{+}{ }^{+} \mathrm{T}$-cells enhance $\mathrm{CD}^{+} \mathrm{T}$ cells develope and help B-cell responses through the activation of antigen-presenting cells or the secretion of cytokines, such as IFN- $\gamma$, IL-2 [37,38]. Compared with the intramuscular immunization DNA vaccine, introduction of attenuated Salmonella further enhanced Th1 cell-mediated immunity with higher levels of IFN- $\gamma$ and IL-2 but low levels of IL-4 and IL-5. These results clearly demonstrate that attenuated Salmonella BRD509 can significantly augment Th1-type cellular immune responses in BALB/c mice. Both T-cell subsets are important sources of IFN- $\gamma$. Optimal protective $\mathrm{CD}^{+} \mathrm{T}$ cell responses depend on the ability of $\mathrm{CD}_{4}{ }^{+} \mathrm{T}$-cells to provide the growth factor IL-2.

In this study, a highly virulent $\mathrm{RH}$ strain of $T$. gondii was used for challenge study. When challenged with lethal doses of $T$. gondii $\left(1 \times 10^{3}\right)$ all three immunization groups prolonged survival time compared to control mice. Especially, mice immunized perorally had a $60 \%$ survival rate. There was somewhat less enhancement of survival (40\%) following intranasal immunization, while only a $20 \%$ survival rate was achieved following intramuscular immunization. In the future, a cystforming PRU strain of $T$. gondii will be used to evaluate the protective potency of this recombinant Salmonella vaccine via the mucosal immunization route. 


\section{Conclusion}

In summary, multi-epitope vaccines delivered by attenuated Salmonella are a promising way to elicit protective immune responses. Compared to intramuscular injection, oral and nasal immunizations with recombinant Salmonella elicits both systemic and mucosal immune responses, accompanied by a significant increase in survival rates in vaccinated mice after challenge with highly virulent parasites. The results from this study should contribute to development of highly protective mucosal vaccines against $T$. gondii.

\section{Competing interests}

The authors declare that they have no competing interests with this publication.

\section{Authors' contributions}

$\mathrm{HC}$ carried out the vaccine construction and drafted the manuscript. XZ performed the immune response analysis. XZ and LZ performed the animal experiments. QY and ZW participated in the design of the study. QY performed the statistical analysis. $\mathrm{YZ}$ and $\mathrm{SH}$ made a revision of the manuscript. All authors have read and approved the final manuscript.

\section{Acknowledgments}

This study was supported by grants from the National Natural Science Foundation Project of China (Grant No. 81171604, No. 81271857 and No. 31170906) and China Postdoctoral Science Foundation (Grant No. 20110491573).

\section{Author details}

${ }^{1}$ Department of human parasitology, Medical school, Shandong University, No.44 Wenhuaxi Road, Jinan, Shandong 250012, P. R. China. ${ }^{2}$ School of Mechanical Engineering, Shandong University, Jinan, Shandong 250061, P. R. China. ${ }^{3}$ School of Public Health, Shandong University, No.44 Wenhuaxi Road, Jinan, Shandong 250012, P. R. China.

Received: 24 August 2013 Accepted: 21 March 2014

Published: 31 March 2014

\section{References}

1. Zhou P, Chen Z, Li HL, Zheng H, He S, Lin R, Zhu XQ: Toxoplasma gondii infection in humans in China. Parasit Vectors 2011, 4:165.

2. Mwambe B, Mshana SE, Kidenya BR, Massinde AN, Mazigo HD, Michael D, Majinge C, Groß U: Sero-prevalence and factors associated with Toxoplasma gondii infection among pregnant women attending antenatal care in Mwanza, Tanzania. Parasit Vectors 2013, 6:222.

3. McLeod R, Kieffer F, Sautter M, Hosten T, Pelloux H: Why prevent, diagnose and treat congenital toxoplasmosis? Mem Inst Oswaldo Cruz 2009, 104:20-344.

4. Wang L, Cheng HW, Huang KQ, Xu YH, Li YN, Du J, Yu L, Luo QL, Wei W Jiang L, Shen JL: Toxoplasma gondii prevalence in food animals and rodents in different regions of China: isolation, genotyping and mouse pathogenicity. Parasit Vectors 2013, 6:273.

5. Couper KN, Nielsen HV, Petersen E, Roberts F, Roberts CW, Alexander J: DNA vaccination with the immunodominant tachyzoite surface antigen (SAG-1) protects against adult acquired Toxoplasma gondii infection but does not prevent maternofoetal transmission. Vaccine 2003 21(21-22):2813-2820.

6. Sun XM, Zou J, Elashram Saeed AA, Yan WC, Liu XY, Suo X, Wang H, Chen QJ: DNA vaccination with a gene encoding Toxoplasma gondii GRA6 induces partial protection against toxoplasmosis in BALB/C mice. Parasit Vectors 2011, 4:213.

7. Rashid I, Hedhli D, Moiré N, Pierre J, Debierre-Grockiego F, Dimier-Poisson I, Mévélec MN: Immunological responses induced by a DNA vaccine expressing RON4 and by immunogenic recombinant protein RON4 failed to protect mice against chronic toxoplasmosis. Vaccine 2011, 29(48):8838-8846.
8. Zhang NZ, Chen J, Wang M, Petersen E, Zhu XQ: Vaccines against Toxoplasma gondii: new developments and perspectives. Expert Rev Vaccines 2013, 12(11):1287-1299.

9. Yan HK, Yuan ZG, Song HQ, Petersen E, Zhou Y, Ren D, Zhou DH, Li HX, Lin $R Q$, Yang GL, Zhu XQ: Vaccination with a DNA vaccine coding for perforin-like protein 1 and MIC6 induces significant protective immunity against Toxoplasma gondii. Clin Vaccine Immunol 2012, 19(5):684-689.

10. Qu D, Han J, Du A: Evaluation of protective effect of multiantigenic DNA vaccine encoding MIC3 and ROP18 antigen segments of Toxoplasma gondii in mice. Parasitol Res 2013, 112(7):2593-2599.

11. Cong H, Zhang M, Xin Q, Wang Z, Li Y, Zhao Q, Zhou H, He S: Compound DNA vaccine encoding SAG1/ SAG3 with $A 2 / B$ subunit of cholera toxin as a genetic adjuvant protects BALB/c mice against Toxoplasma gondii. Parasit Vectors 2013, 6:63.

12. Cong H, Gu QM, Yin HE, Wang JW, Zhao QL, Zhou HY, Li Y, Zhang J: Multi-epitope DNA vaccine linked to the A2/B subunit of cholera toxin protect mice against Toxoplasma gondii. Vaccine 2008, 26(31):3913-3921.

13. Cong H, Zhang M, Zhang Q, Gong J, Cong H, Xin Q, He S: Analysis of structures and epitopes of surface antigen glycoproteins expressed in bradyzoites of Toxoplasma gondii. BioMed Res Inter 2013, 2013:165342.

14. Zhang M, Zhao L, Song J, Li Y, Zhao Q, He S, Cong H: DNA vaccine encoding the Toxoplasma gondii bradyzoite-specific surface antigens SAG2CDX protect BALB/c mice against type II parasite infection. Vaccine 2013, 31(41):4536-4540.

15. Mohamed RM, Aosai F, Chen M, Mun HS, Norose K, Belal US, Piao LX, Yano A: Induction of protective immunity by DNA vaccination with Toxoplasma gondii HSP70, HSP30 and SAG1 genes. Vaccine 2003, 21(21-22):2852-2861.

16. Gahan ME, Webster DE, Wijburg OL, Wesselingh SL, Strugnell RA: Impact of prior immunological exposure on vaccine delivery by Salmonella enterica serovar Typhimurium. Vaccine 2008, 26(49):6212-6220.

17. Daiji A, Lage zur S, Garbe Al, Chakraborty T, Weiss S: Oral delivery of DNA vaccines using attenuated Salmonella typhimurium as carrier. Immunol Med Microbiol 2000, 27:341-349.

18. Liu XB, Liang AX, Feng XG, Guo AZ, Ke CY, Zhang SJ, Yang LG: Oral and intranasal administration of somatostatin DNA vaccine mediated by attenuated Salmonella Enterica Serovar Typhimurium to promote growth of piglets. Animal 2011, 5(8):1231-1236.

19. Chin'ombe N: Recombinant Salmonella enterica serovar Typhimurium as a vaccine vector for HIV-1 Gag. Viruses 2013, 5(9):2062-2078.

20. Eom JS, Kim JS, Im Jang J, Kim BH, Yoo SY, Choi JH, Bang IS, Lee IS, Park YK: Enhancement of host immune responses by oral vaccination to Salmonella enterica serovar Typhimurium harboring both FliC and FljB flagella. PLoS One 2013, 8(9):e74850

21. Cong H, Gu QM, Jiang Y, He S, Zhou HY, YANG TT, Li Y, Zhao QL: Oral immunization with recombinant attenuated Salmonella protect mice against Toxoplasma gondii. Parasit Immunol 2005, 27(1-2):29-35.

22. Meng M, He S, Zhao G, Bai Y, Zhou H, Cong H, Lu G, Zhao Q, Zhu XQ: Evaluation of protective immune responses induced by DNA vaccines encoding Toxoplasma gondii surface antigen 1 (SAG1) and 14-3-3 protein in BALB/c mice. Parasit Vectors 2012, 5:273.

23. Chen J, Huang SY, Zhou DH, Li ZY, Petersen E, Song HQ, Zhu XQ: DNA immunization with eukaryotic initiation factor-2a of Toxoplasma gondii induces protective immunity against acute and chronic toxoplasmosis in mice. Vaccine 2013, 31(52):6225-6231

24. Yan HK, Yuan ZG, Song HQ, Petersen E, Zhou Y, Ren D, Zhou DH, Li HX, Lin RQ, Yang GL, Zhu XQ: Vaccination with a DNA vaccine coding Perforin-like Protein 1 (TgPLP1) and MIC6 induces significant protective immunity against Toxoplasma gondii. Clin Vaccine Immunol 2012, 29:684-689.

25. Zhao G, Zhou A, Lu G, Meng M, Sun M, Bai Y, Han Y, Wang L, Zhou H, Cong $\mathrm{H}$, Zhao Q, Zhu XQ, He S: Identification and characterization of Toxoplasma gondii aspartic protease 1 as a novel vaccine candidate against toxoplasmosis. Parasit Vectors 2013, 6:175.

26. Henriquez FL, Woods S, Cong H, McLeod R, Roberts CW: Immunogenetics of Toxoplasma gondii informs vaccine design. Trends Parasitol 2010, 26(11):550-555.

27. Zhao L, Zhang M, Cong H: Advances in the study of HLA-restricted epitope vaccines. Hum Vaccin Immunother 2013, 9(12):1-12.

28. Cong H, Mui EJ, Witola WH, Sidney J, Alexander J, Sette A, Maewal A McLeod R: Towards an immunosense vaccine to prevent toxoplasmosis: Protective Toxoplasma gondii epitopes restricted by HLA-A*0201. Vaccine 2011, 29(4):754-762. 
29. Del L, Yácono M, Farran I, Becher ML, Sander V, Sánchez VR, Martín V, Veramendi J, Clemente M: A chloroplast-derived Toxoplasma gondii GRA4 antigen used as an oral vaccine protects against toxoplasmosis in mice. Plant Biotechnol J 2012, 10(9):1136-1144.

30. Ye L, Zeng R, Bai Y, Roopenian DC, Zhu X: Efficient mucosal vaccination mediated by the neonatal Fc receptor. Nat Biotechnol 2011, 29(2):158-163.

31. Abdul-Wahid A, Faubert G: Mucosal delivery of a transmission-blocking DNA vaccine encoding Giardia lamblia CWP2 by Salmonella typhimurium bactofection vehicle. Vaccine 2007, 25(50):8372-8383.

32. Chin'ombe N, Ruhanya V: Recombinant Salmonella Bacteria Vectoring HIV/AIDS Vaccines. Open Virol J 2013, 7:121-126.

33. Lynch LF, Lynch MI, Ferreira RS, Vasconcelos MS, Melo N, Ferreira S, Malagueño E: Ocular toxoplasmosis: evaluation of lacrimal-specific secretory IgA levels in both patients with active and inactive phases of the disease. Mem Inst Oswaldo Cruz 2011, 106(5):625-628

34. Wang $Y$, Wang $G$, Zhang D, Yin H, Wang M: Screening and identification of novel B cell epitopes of Toxoplasma gondii SAG1. Parasit Vectors 2013, 6:125.

35. Bhadra R, Gigley JP, Khan IA: The CD8 T-cell road to immunotherapy of toxoplasmosis. Immunotherapy 2011, 3(6):789-801.

36. Yarovinsky F: Innate immunity to Toxoplasma gondii infection. Nat Rev Immunol 2014, 14(2):109-121.

37. Jongert E, Lemiere A, Van Ginderachter J, De Craeye S, Huygen K, D'Souza S: Functional characterization of in vivo effector CD4(+) and CD8(+) T cell responses in acute Toxoplasmosis: an interplay of IFN-gamma and cytolytic T cells. Vaccine 2010, 28(13):2556-2564

38. Menard LC, Minns LA, Darche S, Mielcarz DW, Foureau DM, Roos D, Dzierszinski F, Kasper LH, Buzoni-Gatel D: B cells amplify IFN-gamma production by T cells via a TNF-alpha-mediated mechanism. J Immunol 2007, 79(7):4857-4866.

doi:10.1186/1756-3305-7-145

Cite this article as: Cong et al: Comparative efficacy of a multi-epitope

DNA vaccine via intranasal, peroral, and intramuscular delivery against lethal Toxoplasma gondii infection in mice. Parasites \& Vectors 2014 7:145.

\section{Submit your next manuscript to BioMed Central and take full advantage of:}

- Convenient online submission

- Thorough peer review

- No space constraints or color figure charges

- Immediate publication on acceptance

- Inclusion in PubMed, CAS, Scopus and Google Scholar

- Research which is freely available for redistribution 